\title{
SOBRE A POÉTICA DE HUBERT DUPRAT ${ }^{1}$
}

\author{
Profa. Dra. Sandra Makowiecky², Luciane Ruschel Nascimento Garcez ${ }^{3}$
}

Palavras-chave: casulos, animal, sagrado.

O projeto trata da pesquisa e análise do trabalho com larvas aquáticas do artista francês Hubert Duprat. O foco da análise é o uso do ouro como material para confecção dos casulos tecidos pelas larvas, sua simbologia na produção artística contemporânea, o conceito de sagrado que vem agregado a este metal, a relação arte/animal presente nesta obra de Duprat, e as questões que este fato levanta como os conceitos de originalidade e autoria.

Este projeto tem como pressuposto fazer um mapeamento e uma leitura da obra de Hubert Duprat, mais especificamente seus casulos em ouro. Fazer uma análise sobre o significado deste material para este artista, o motivo da escolha deste material, o porquê do conceito de sagrado que ele agrega a seu trabalho, qual a relação do o ouro com a obra.

Outro ponto importante na pesquisa é a relação arte/animal presente neste trabalho. Podemos rastrear esta relação até a pré-história, vários são os artistas que andaram por esta clave, e vários são os teóricos que refletiram sobre esta questão.

Pode-se dizer, nas palavras do teórico francês Michel Foucault, que o primeiro olhar ao se analisar um trabalho com tamanha sensibilidade como os casulos de Duprat, é um "espetáculo-de-olhares" (FOUCAULT, 1995, p.29), onde é possível embevecer-se com a beleza da obra, observar sua construção formal, suas linhas e volumes, mas também ir mais fundo e questionar sobre a intenção do artista e do material de sua escolha, seus questionamentos e reflexões.

A idéia é fazer a análise a partir desta obra onde o artista usa um tipo de larva aquática, as tricópteras, que tecem seus casulos com os materiais que encontra à sua disposição nos leitos dos rios. Ele as encerra em aquários e disponibiliza, a princípio, alguns fios e pepitas de

${ }^{1}$ Projeto de Pesquisa PPGAV - CEART, UDESC.

${ }^{2}$ Orientadora, Professora do Centro de Artes - Graduação e Programa de Pós-Graduação em Artes Visuais UDESC.

${ }^{3}$ Mestranda regularmente matriculada no PPGAV/2007 - CEART, UDESC.

DAPesquisa, Florianópolis, v.2, n.4, p. 220-228, 2007. 
ouro, durante o processo, conforme o desenvolvimento do casulo, ele vai agregando ao material disponível para as larvas, pérolas, turquesas, âmbar entre outras pedras preciosas e semipreciosas para que teçam seus casulos como se fossem jóias (ver fig. 1, 2 e 3). Estas peças são fotografadas assim como o processo de confecção que é também filmado, já que o resultado final não tem um caráter de permanência (uma vez que o que mantém o casulo unido é uma espécie de fios de seda expelidos pelas glândulas das larvas, e como se sabe sem solda as peças de ouro não conseguem se manter ligadas). As fotos são expostas em galerias, assim como o filme que mostra as larvas trabalhando; em algumas mostras o artista colocou os aquários pendurados nas paredes, à altura dos olhos do espectador, contendo as larvas em seu interior em pleno processo de confecção do casulo, como se fossem quadros. Neste procedimento o artista levanta uma reflexão sobre a sobrevivência da arte em museus e galerias no formato mais tradicional até meados do século $\mathrm{XX}$, e que na atualidade tem sido discutido em várias instâncias da arte contemporânea. Não só o resultado de seu trabalho e processo de criação são polêmicos, a maneira como ele revela suas larvas também provoca o espectador a pensar um pouco mais sobre a arte no século XXI, a relação arte/animal/natureza e tecnologia. Este procedimento de confecção dos casulos foi patenteado pelo artista para se proteger dos ourives e joalheiros.

Nesta obra podemos identificar uma intensa relação com a religião, já que o artista faz referência à idéia do sagrado, e vai mais longe, em entrevista à autora ${ }^{4}$ ele comenta que a escolha pelo material se dá pelo seu "manto religioso", citando o teórico francês, Roger Caillois.

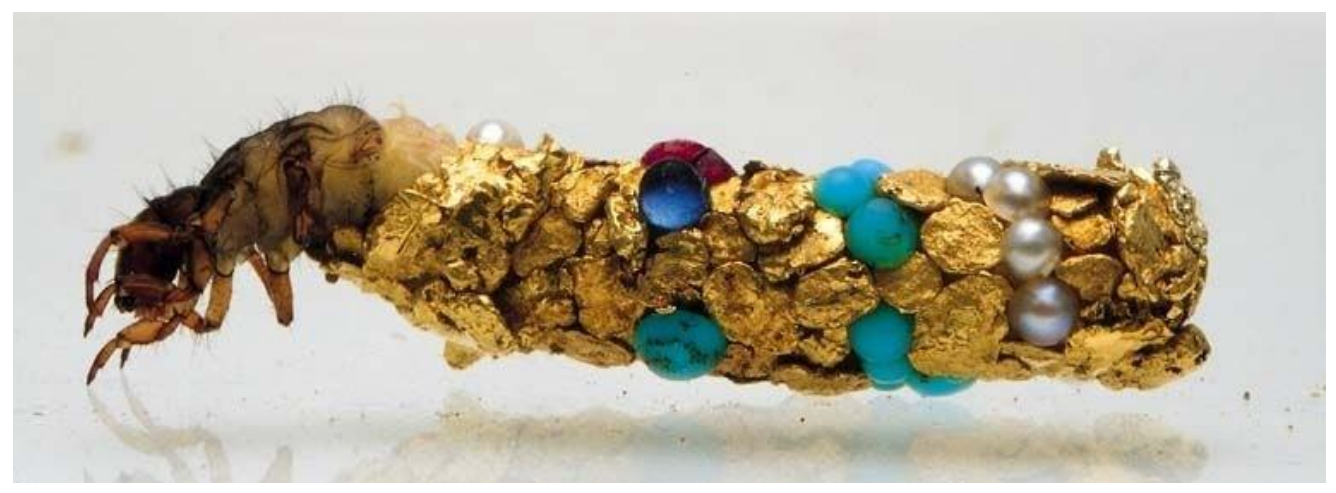

Fig. 1

\footnotetext{
${ }^{\overline{4}}$ Via e-mail em maio de 2006.
} 


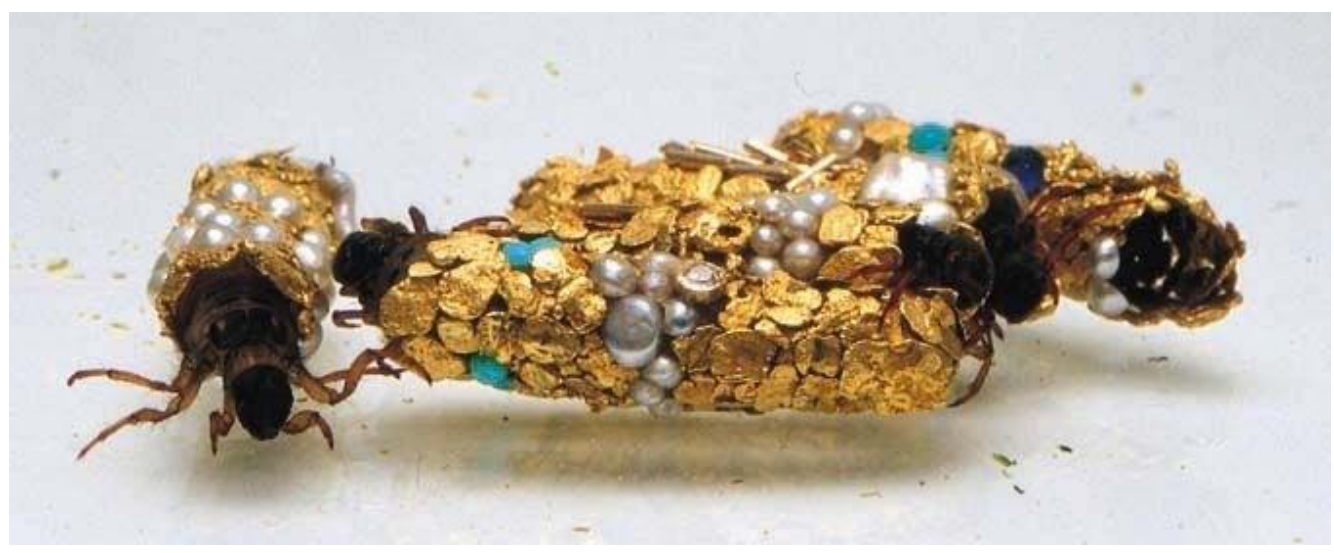

Fig. 2

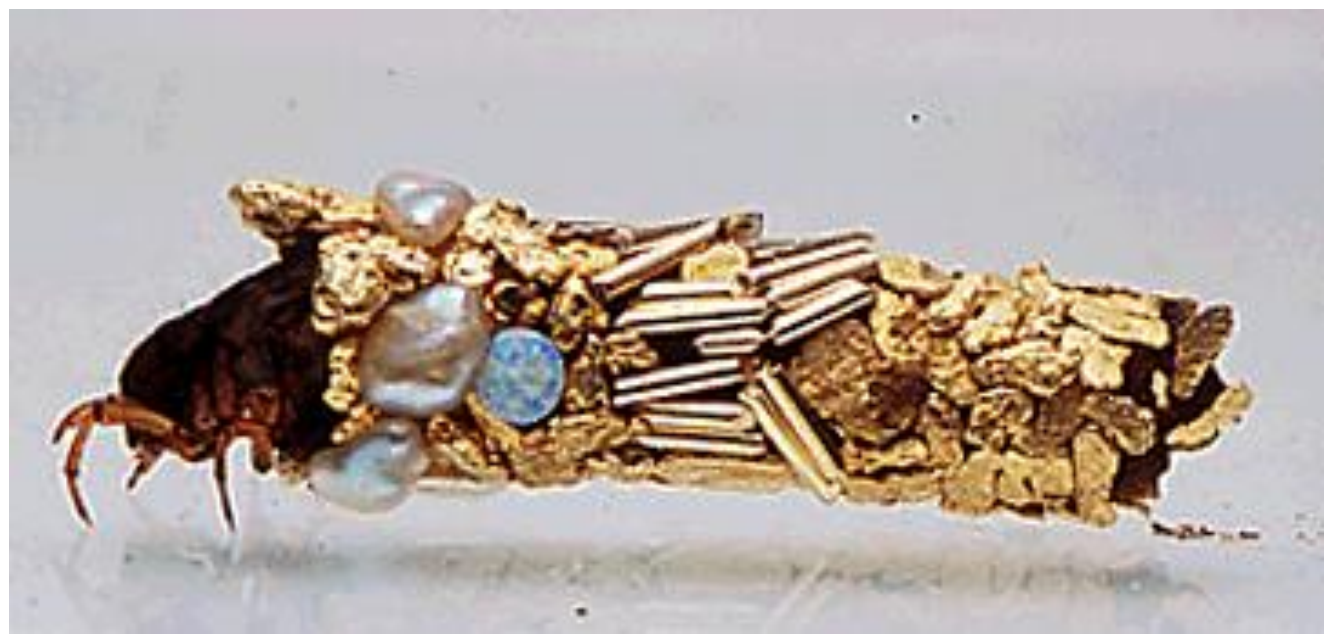

Fig. 3

$\mathrm{Na}$ história da joalheria pode-se identificar uma ligação muito forte entre ouro e religião, ouro e sagrado. Em seu texto sobre o nascimento da arte, Geroges Bataille (2003, P. 16) faz esta mesma colocação a respeito de arte e religião. Neste mesmo percurso, encontra-se o animal como fonte de inspiração e objeto de pesquisa na arte; no caso de Duprat, mais do que uma relação o animal é o próprio artesão, as larvas são como operárias que confeccionam a obra. A este respeito levanta-se a questão da autoria, quem seria o autor da obra? $\mathrm{O}$ artista ou a larva? Como se classifica esta obra, onde o artista é um maestro que rege suas larvas e coordena a construção dos casulos? As larvas vêm construindo estas crisálidas desde 1983, Duprat as mantêm em aquários em seu atelier; são miniaturas em ouro e pedras que são confeccionadas, uma após a outra. Algumas se desmancham mais rápido que as outras e neste 
caso Duprat reutiliza o material. Seriam cópias sem matriz? Ou cada casulo é seu próprio original? Para auxiliar nesta reflexão da repetição sem fim, vai-se contar com Rosalind Krauss e seu texto La originalidad de la Vanguardia (1996), onde ela analisa uma exposição do escultor francês Auguste Rodin, em Washington, em 1978. Nesta mostra existem peças confeccionadas anos após sua morte e que são expostas como “originais” de Rodin. O escultor doou ao Estado francês, além de todos seus pertences, também o direito de reproduzir em bronze suas obras de marmorite. A partir deste texto pretende-se pensar a questão da autoria e da reprodução infinita, questões importantes no trabalho de Hubert Duprat. A relação ouro/animal, presente nos casulos, fascina o espectador, é interessante buscar neste estudo por quais caminhos o ouro leva o artista a trilhar um percurso.

Olhar os casulos de Duprat é fazer um passeio, um passeio sem rota definida, sem guia que o oriente, é fazer um percurso aleatório de maravilhamento. Pensar estes casulos é como fazer um empilhamento de idéias, conceitos, períodos, um emaranhado de informações que aos poucos vão se contaminado entre si e fazendo sentido, é como olhar uma pérola que com suas camadas irregulares vão formando um conceito. Giles Deleuze e Felix Guattari, em $O$ que é a Filosofia?, comentam: “A arte conserva, e é a única coisa no mundo que se conserva. Conserva e se conserva em si (quid júris?), embora, de fato, não dure mais que seu suporte e seus materiais (quid facti?)" (DELEUZE, GUATTARI, 1992, p. 213), aqui também é a efemeridade da obra que está em jogo, apesar do material ser dos mais duráveis que a natureza pode oferecer, o resultado é efêmero, seu registro é o que fica, a sensação é o que perdura. Alberto Manguel fala em seu texto Lendo Imagens, “... se nem metal nem mármore irão durar, por que então não aceitar sua transitoriedade como sendo em si um monumento?’ (MANGUEL, 2003, p. 276), esta transitoriedade está presente e é elemento importante do trabalho de Duprat, depois do casulo o que restam são fragmentos, pedaços de um casulo-casa, memórias desencontradas de uma obra que está por recomeçar. E aí vem um novo casulo, uma outra imagem.

Olhar esses casulos é também um ato anacrônico, pelas questões que ele levanta, por sua forma, seu efeito, pelos conceitos que estão agregados a estes trabalhos. É possível localizá-los na arte egípcia, com seus insetos, joalheria e arte andando juntas, pelo sagrado tão forte nesta cultura; é possível olhar esses casulos por seu aspecto decorativo, no período barroco, com suas ostentações e excessos, o dourado como elemento principal em certas obras; 
pode-se pensá-los na arte contemporânea, com sua questão formal na relação arte/animal e a pesquisa e tecnologia necessárias para a concretização do projeto, ciência e arte juntas. Para pensar nesta clave, vai-se ler o teórico Georges Didi-Huberman e seu texto Ante el tiempo (2005), onde o conceito de anacrônico é amplamente discutido.

É a partir destas idéias que se vai iniciar esta pesquisa. Investigar o que motivou o artista a optar pelo mais nobre dos metais, tentar fazer toda esta gama de relações e conexões, ler seu trabalho com a mesma paixão e fascinação com que ele o executa.

Um dos pontos da pesquisa é buscar identificar quais valores são atribuídos ao ouro por conta do artista, com que conotação ele é usado e, ainda, quais as referências que o levou a tal escolha. Ao longo da história o ouro passou por diversos momentos, mas geralmente esteve ligado ao poder, à riqueza, ao sagrado. A nobreza e o clero foram ávidos consumidores e usaram e abusaram do ouro de diversas maneiras. Nesta pesquisa existe o desejo de, simultaneamente às leituras das obras do artista pesquisado, conectá-las a certos períodos históricos onde se buscava trabalhar a idéia do valor atribuído ao ouro, de maneira semelhante. Talvez a possibilidade de seguir por este caminho traga um grande referencial teórico que em muito enriqueceria este projeto.

Conforme Pseudo-Dionísio Aeropagita (final séc. V- início séc. VI IN: LICHTENSTEIN, 2004), em seu texto A Origem Divina das Imagens, do fim do século V, início do século VI, onde fala sobre a sacralização da imagem, como Deus se revelaria aos homens, quando uma imagem se torna sagrada, a este respeito ele comenta:

... é necessário dizer que a revelação divina é dupla: uma procede das imagens sagradas adequadas a cada objeto, a outra apresenta a inadequação das formas que ela modela até a mais profunda dessemelhança, mesmo até o absurdo. Este tipo de revelação mística é própria das Escrituras, uma vez que ela celebra a virtuosa beatitude do Princípio Divino Transcendente através de nomes como razão, inteligência, essência (...). Tais representações são, de fato, mais sagradas e superiores que imagens materiais, mas, em verdade, elas não são menos deficientes que as outras quando é necessário representar, em toda sua verdade, o Princípio Divino que ultrapassa qualquer essência ou existência, em nada se parece com qualquer luz, e do qual nenhuma inteligência ou razão poderiam fornecer uma imagem confiável. (...) Assim, se todas as negações são verdadeiras no que diz respeito aos mistérios divinos, ao passo que qualquer afirmação é inadequada, é natural que as realidades divinas sejam melhor representadas por imagens que não guardam nenhuma relação com seu modelo. 
Em todo momento da história encontram-se exemplos de imagens e situações que o homem tende a sacralizar. Não só o objeto em si, mas a atitude do criador e o caminho trilhado por ambos tornam estas obras sagradas aos olhos do mundo. O objeto se torna sacro por diversas manifestações, não necessariamente ligadas diretamente à religião. Mircea Eliade (1995, p. 18), no texto O Sagrado e o Profano, diz que:

Manifestando o sagrado, um objeto qualquer torna-se outra coisa e, contudo, continua a ser ele mesmo, porque continua a participar do meio cósmico envolvente. Uma pedra sagrada nem por isso é menos uma pedra; aparentemente (para sermos mais exatos, de um ponto de vista profano) nada a distingue de todas as demais pedras. Para aqueles a cujos olhos uma pedra se revela sagrada, sua realidade imediata transmuda-se numa realidade sobrenatural.

Os besouros egípcios, que se referiam ao sol e à criação, e que, há aproximadamente 4.500 anos, são confeccionados e usados na joalheria deste país (PHILIPS, 1996, p.12). São exemplos de peças artísticas onde o animal está aliado à arte e ao ouro, no caso dos besouros egípcios, confeccionados também em turquesa e que são símbolos sagrados para seu povo, símbolos de luz que ainda hoje carregam um "manto religioso" sobre estas peças.

Para auxiliar na reflexão sobre a representação do animal na arte conta-se com Jacques Derrida em seu texto $O$ animal que logo sou (2002). Nele, Derrida inicia uma discussão a partir de uma experiência onde se viu nu observado por seu gato; essa experiência o fez constatar que na relação dos homens com os animais, há duas possibilidades. Uma é o homem observar o animal e nele, muitas vezes, projetar sua própria psique e sentimentos, o que gera inúmeras metáforas e fábulas onde os animais - então humanizados -recebem um papel importante, esta é a mais freqüente. A outra, mais complicada, somente tentada por "poetas e profetas" (2002, p. 34), é tentar imaginar como o animal nos vê, não lhe atribuindo nossas características e sim tentando criar este impossível: ver-nos como um animal nos vê - tal como ele mesmo, Derrida, se viu observado nu por um gato. A própria questão da nudez já marca a imensidão do abismo que nos separa, a nós homens, dos animais. Derrida, em sua desconstrução do conceito animal, faz duas proposições - uma é evidenciar a enorme agressividade e destrutividade praticada pelos homens contra estes outros viventes que chamamos animais, coisa que nos últimos dois séculos atingiu níveis nunca antes alcançados. Neste período as formas tradicionais de 
tratamento do animal foram subvertidas, é evidente e pode-se comprovar este fato observando as técnicas de intervenção e transformação do objeto, o vivente animal: pela criação e adestramento em uma escala demográfica sem nenhuma comparação com o passado, pelas experiências genéticas, pela industrialização do que se pode chamar a produção alimentar de carne animal, pela inseminação artificial, pela redução do animal não apenas à produção e reprodução superestimuladas (hormônios, cruzamentos genéticos, clonagens, etc.) de carne alimentícia, mas a todas as outras finalidades a serviço de um suposto bem-estar humano (2002, p. 51). É através desse inegável sofrimento que podemos nos aproximar dos animais e superar a negação que permite o atual trato da questão, abrindo espaço para o respeito com a vida, seja qual for sua manifestação. Onde se enquadra o uso das larvas por Duprat nesta reflexão?

A segunda proposição de Derrida diz respeito à forma defensiva com a qual a palavra animal é usada, que não faz justiça à enorme variedade de formas animais e à conseqüente singularidade das relações que o homem pode estabelecer com elas. Ao desconstruir conceitos e categorias de animal, chamando-nos a todos de viventes e animots, Derrida não apaga os limites e o abismo que nos separa dos animais. Mas mostra como o que nos é próprio fica às vezes muito pouco claro. Faz-nos encarar o enigma da vida e o respeito que lhe devemos.

Em resumo, pode-se dizer que é com a ajuda de Bataille, Caillois, Deleuze, Mircea Eliade, Guattari, Rosalind Krauss e Derrida entre outros já citados, que esta pesquisa tentará ler e mapear a importância do ouro na obra de alguns artistas contemporâneos, para buscar entender, mais amplamente, algumas de suas múltiplas significações simbólicas e a relação do animal, presente na arte há milhares de anos, bem como o conceito de sagrado que ambos despertam, e despertaram, em diversas culturas e momentos da história.

\section{REFERÊNCIAS:}

AEROPAGITA, Pseudo-Dionísio. A origem divina das imagens - Hierarquia celeste, I, II; Hierarquia eclesiástica, IV. IN: LICHTENSTEIN, Jacqueline. A Pintura - Textos Essenciais. Vol. 2, A teologia da imagem e o estatuto da pintura. $1^{\text {a }}$ Edição. São Paulo: Editora 34 Ltda., 2004. 
BATAILLE, Georges. Lascaux o El Nacimiento del Arte. Argentina: Alción Editora, 2003.

DELEUZE, Giles; GUATTARI, Felix. O que é a Filosofia? São Paulo: Editora 34, 1992.

DERRIDA, Jacques. O Animal que Logo Sou. São Paulo: UNESP, 2002.

DIDI-HUBERMAN, Georges. Ante el tiempo. Argentina: Adriana Hidalgo editora S. A., 2005.

ELIADE, Mircea. O Sagrado e o Profano: A essência das religiões. São Paulo: Martins Fontes, 1995.

FOUCAULT, Michel. As palavras e as coisas. 7. Ed. São Paulo: Martins Fontes, 1995.

KRAUSS, Rosalind E. La originalidad de la Vanguardia y otros mitos modernos. Madrid: Alianza Editorial S.A., 1996.

MANGUEL, Alberto. Lendo Imagens. 2. Ed. São Paulo: Companhia das Letras, 2003.

PHILIPS, Clare. Jewelry - From Antiquity to the Present. London: Thames and Hudson Ltd, 1996.

\section{BIBLIOGRAFIA SUPLEMENTAR:}

AUDINET, Éric. L'Envers du Paysage et Entretien avec Hubert Duprat. In Magazine, n. 2, Galerie Images Nouvelles/Jean-François Dumont, Bordeaux, février 1986.

BESSON, Christian e DUPRAT, Hubert. Wonderful Caddis- Worm. Leonardo,Vol.31, n³, p. 173 - 177, San Francisco, juin 1998.

BRIGNONE, Patricia. Hubert Duprat, le Creux de l'Enfer. Parachute n ${ }^{\circ}$, p. 33, Montréal, janvier 1995.

CHALOIN, Françoise. La perception n'a pas d'objet. Cahiers Arts et Sciences, n² 2, p.130143, Bordeaux, 1995.

CHALOIN, Françoise. Cuatro obras, cuatro notas. BELLIDO, Ramon Tio. Lima/Cuzco/Lima o Hubert Duprat en el Altiplano. Hubert Duprat - Sale Arte Contemporaneo Luis Miro Quesada Garland. Miraflores-Lima, 2001.

CHATEL, Louis IN : BESSON, Christian (Org.). Hubert Duprat Theatrum - Guide imaginaire des collections. Collection reConnaître. Paris: Musée départemental (Digne), Philippe Grand, Antenne Éditoriale de Lyon, 2002. 
FOUGÈRE, Isabelle. Hubert Duprat et les trichoptères. Recherches Poiétiques: L'Animal vivant dans l'art contemporain, Valenciennes, n. 9, p.80-85, Juin 2000.

PAUL, Frédéric. La bibliothèque de l'instituteur: Hubert Duprat, archéologie et macération. Les Cahiers: du Musée national d'art moderne, Paris, Centre Pompidou, n. 72, p.57-79, Été 2000 .

RENIÉ, Guy-Marie. Sedges baroques de Hubert Duprat. Première catégorie, Vol 2, nº 3, p. 3232-35, Aramits, 1988.

WEINTRAUB, Linda. Hubert Duprat, In the Making: Creative Options for Contemporary Art, d.a.p, p. 174-181, New York, 2003. 